\title{
Correspondence
}

\section{Rheumatism in retrospect}

Sir,

As World Rheumatism Year has now closed, it might be of value for the younger supporters, who have always been 'respectable', to learn of our pre-War problems.

When I passed my Membership in 1933, by luck first time, I suddenly realised that I could not have given a reasonable answer to a question on rheumatoid arthritis, although $I$ had at my fingertips details of every obstruse cerebral condition known. I therefore went to my chief, Professor Sir Francis Fraser, and told him I wished to make a part-time study of the rheumatic diseases. His reply was, 'My boy, I have been training you to be a respectable physician at Barts and you now decide to prostitute your soul by associating with every quack in the Universe'. My reply-'How then can Medicine improve?' He then helped me all he could. The only rheumatologist at that time with any senior degree was Will Copeman and even he was suspect for his interest and I certainly took a step down the ladder. Horder, the clinician of this century, was the one visionary when he founded the Empire Rheumatism Council, now the Arthritis and Rheumatism Council, in 1936, with Will Copeman as medical secretary and myself about the most junior member. A year later the Heberden Society was conceived by the staff of the Peto Place British Red Cross Society Rheumatology Clinic.

Gradually rheumatology became respectable, helped by the discovery of cortisone by an American rheumatologist,
Phil Hench. Now we have five Chairs and three majo specialist research units and every scientist values ب़่s importance. But still, under the NHS, though it cơnstitutes a third of the complaints to GPs, it is funded ogy only $4.5 \%$ of the budget.

Physical medicine and rehabilitation had the same difficult beginnings and again Horder sorted it out. The War made rehabilitation important but the Barons. Jf Harley Street (led by Morton Smart and Robert Stanton Woods), the Emergency Medical Service (Frank Cooksesp, and Service specialists (Frank Howitt), and other spectialists, like Philippe Bauwens, world authority on mediegl electricity, but uninterested in other problems, wete fighting like cats and dogs, till Horder gave a lunch party at Claridges in 1942 and figuratively bumped thoir heads together. The result was the British Association $\approx f$ Physical Medicine.

When will manipulative medicine be properly brought into the medical curriculum and receive the cloak of respeztability? As Horder once wrote, 'It takes a lowg time for the Princes of Medicine to take Cinderella to dance', though today they do a little more readily their eyes rove over the form. Royal National Hospital for Rheumatic Diseasts, Upper Borough WaAs, Bath BA1 1RI.

\section{Errata}

In the paper 'Alclofenac and D-penicillamine' by $\mathrm{H}$ Berry et al. (pp. 93-97, February issue), the sentencegin the second paragraph of the Discussion, 'It disappeared on stopping the drug but did not recur when patient was rechallenged' should read 'It disappeared on stopping the drug but recurred when the pationt was rechallenged'.

The Second Prague Symposium on Rheumatology-Spinal Column, will be held from June 11th-14 1978, not July 12th-15th as published in the December issue of the Annals, 36, 591. 